\title{
Many ways to die, one way to arrive: how selection acts through pregnancy
}

\section{Citation}

Brown, Elizabeth A., Maryellen Ruvolo, and Pardis C. Sabeti. 2013. "Many Ways to Die, One Way to Arrive: How Selection Acts through Pregnancy." Trends in Genetics 29 (10) (October): 585-592. doi:10.1016/j.tig.2013.03.001.

\section{Published Version}

doi:10.1016/j.tig.2013.03.001

\section{Permanent link}

http://nrs.harvard.edu/urn-3:HUL.InstRepos:34298867

\section{Terms of Use}

This article was downloaded from Harvard University's DASH repository, and is made available under the terms and conditions applicable to Open Access Policy Articles, as set forth at http:// nrs.harvard.edu/urn-3:HUL.InstRepos:dash.current.terms-of-use\#OAP

\section{Share Your Story}

The Harvard community has made this article openly available.

Please share how this access benefits you. Submit a story.

Accessibility 
Many Ways to Die; One Way to Arrive:

How selection acts through pregnancy

Authors: Elizabeth A. Brown' ${ }^{1}$, Maryellen Ruvoloํㅜ Pardis C. Sabeti ${ }^{2,3,4}$

Author Institutions:

1Department of Human Evolutionary Biology, Harvard University, Cambridge, MA 02138, USA.

${ }^{2}$ Center for Systems Biology, Department of Organismic and Evolutionary Biology, Harvard University, Cambridge, MA 02138, USA.

${ }^{3}$ Broad Institute of the Massachusetts Institute of Technology and Harvard, Cambridge, MA 02142, USA.

${ }^{4}$ Department of Immunology and Infectious Diseases, Harvard School of Public Health, Boston, MA 02115, USA.

Corresponding Author: Sabeti, P. (psabeti@oeb.harvard.edu)

Keywords: selection, pregnancy, human evolution, gestational diabetes, preeclampsia Abstract

When considering selective forces shaping human evolution, the importance of pregnancy to fitness should not be underestimated. Although specific mortality factors may only impact a fraction of the population, birth is a funnel through which all individuals must pass. Human pregnancy places exceptional energetic, physical, and immunological demands on the mother to accommodate the needs of the fetus, making the woman more vulnerable during this time period. Here, we examine how metabolic imbalances, infectious 
diseases, oxygen deficiency, and nutrient levels in pregnancy can exert selective pressures on women and their unborn offspring. Numerous candidate genes under selection are being revealed by next-generation sequencing, providing the opportunity to further study the relationship between selection and pregnancy. This relationship is important to consider to gain insight into recent human adaptations to unique diets and environments worldwide.

\section{Selection and Pregnancy}

Some of the earliest records of mortality from London in John Graunt's "Bills of Mortality" for 1632 reveal a number of distinct causes of death in the population [1]. Any specific cause of death impacts only a fraction of the population, lessening each particular factor's importance to fitness (Figure 1). Managing to be born, however, is a universal requirement for fitness. Thus, factors that influence fecundity and pregnancy are likely to strongly shape human evolution.

The many physiological compromises of pregnancy make it a tremendous challenge for both mothers and infants and a potential selective force. In order to provide for the growing fetus, mothers increase blood sugar [2], blood volume, and hemoglobin count [3]; remodel uterine arteries [4]; and decrease vascular resistance [5]. These changes put the mother at risk of diabetes, high blood pressure, strokes, hemorrhaging, and seizures [2, 68]. Moreover, properties of the immune system are down-regulated to prevent immune response to the "foreign" fetus, potentially contributing to pregnant women's greater susceptibility to infectious disease [9]. 
These difficulties for mothers translate into problems for infants as well: preindustrial data show nearly a quarter of babies died during labor and infancy, while maternal mortality was nearly $1.5 \%$ per birth due to infectious diseases, diabetes, eclampsia, and jaundice [10]. Similarly, modern foraging populations and sub-Saharan African nations in 1970 also had infant mortality rates of $20 \%$ to $25 \%$, in contrast to Norway, for example, at only $\sim 1.6 \%[11,12]$. Maternal mortality in sub-Saharan Africa was $\sim 1.0 \%$ in the year 2000 (comparable to 16th and 17th century England) with hemorrhage, hypertension (preeclampsia/eclampsia), and infectious diseases as the major causes. By contrast, maternal mortality in Northern Europe was only $0.02 \%$ in the year 2000 [13]. These data from historic, foraging, and developing country populations only serve as rough proxies for the conditions facing humans during recent evolution, but they give some indication of the difficulty of pregnancy experienced by pre-modern foraging and Neolithic populations.

In addition to the challenges of pregnancy, the number of babies a woman births, compounded across generations, can have huge evolutionary impact. For example, landless Finnish women living 1760-1849 had an average of 4.27 babies, whereas landowning women had an average of 4.55 babies: a change in absolute fitness of this magnitude would cause a geometric rise in the number of descendants in a few generations [14] (Figure 2a). The nutritional benefits of the Industrial Revolution (circa 1880) boosted average Finnish fertility to 5.3 babies [15]. Any such increase in fertility from either environmental or genetic factors will dramatically increase women's fitness (Figure 2b). An earlier revolution, the development of agriculture and pastoralism, may have conferred similar fertility benefits, especially to women with genetic mutations allowing them to maximally 
exploit these new resources-lactase persistence, described below, may be an example of this [16]. Furthermore changes in female fertility could have played an important role during human population migrations. For example, a large study of Quebecois settlers indicated that women on the wave front of territory expansion had a fertility $15-20 \%$ advantage and a heritable component for fertility, suggesting that genes influencing fertility may be shaped by selection [17].

Considering the impact of female fertility alongside the challenges of pregnancy may be critical for understanding recent human adaptations. This review explores how selection may have acted through pressures on mothers and infants during pregnancy given the changing environment, diet, and behavior of the last 10,000 years. These factors are critical to bear in mind as opportunities for evolutionary geneticists to generate new adaptive hypotheses proliferate, fueled by next-generation-sequencing data and new statistical tools for predicting adaptive variants in diverse populations.

\section{Metabolic Disorders and Selection during Pregnancy}

Theories of human adaptation surrounding metabolic disorders, such as hypertension and type 2 diabetes, are constrained by the fact that these diseases typically strike at post-reproductive ages. The related disorders of gestational diabetes mellitus (GDM) and preeclampsia (hypertension in pregnancy), however, occur precisely during the critical reproductive period of pregnancy. GDM occurs as a mother's blood glucose level rises to nourish the fetus, increasing risk of maternal diabetes [18]. Preeclampsia occurs as a mother increases blood volume and remodels vasculature for 
fetal ventilation, raising the risk of maternal hypertension [6]. Women predisposed for these conditions can be pushed into metabolic dysfunction.

GDM and preeclampsia are common diseases with grave consequences in pregnancy and thus may strongly impact reproductive fitness. GDM affects $4 \%-20 \%$ of pregnancies in different populations worldwide [19]. It can cause macrosomia, in which the fetus grows too large to fit through the maternal pelvis [20-23]. Before the advent of Caesariansections, GDM could lead to fetal morbidity and mortality and maternal hemorrhage and tearing during delivery $[7,20]$. Preeclampsia is the leading cause of maternal mortality worldwide accounting for $10 \%-19 \%$ of deaths [24-26]. It can cause fetal hypoxia and oxidative stress, low birthweight, and maternal hemorrhage and seizures (eclampsia) if not treated by premature delivery [24]. (See Box 1 for a discussion of high-altitude adaptation and the risks of preeclampsia.)

The rates of GDM and preeclampsia vary significantly in different populations, even when controlling for environmental factors like obesity $[27,28]$. This raises the possibility that selective pressures during pregnancy have fine-tuned metabolism to suit different environments and diets around the world, resulting in the current distribution of disease prevalence. On the other hand, alternative explanations, discussed in Box 2, may also account for these patterns-distinguishing between these competing hypotheses is an important avenue for future research.

Intriguingly, incidence of GDM among modern populations is inversely related to traditional consumption of dietary components known to increase risk for diabetes and GDM (Table 1). These include high glycemic carbohydrates, which produce large glucose responses in the blood, and dairy products, which produce large insulin responses due to 
the effect of whey proteins [29-33]. Europeans have the lowest prevalence of GDM in the world $-3.6 \%$ in a study of over a million births in New York City (NYC) [19]—yet have the longest history of high glycemic diets. In the past 10,000 years, European grain-based agriculture increased carbohydrate consumption to roughly $70 \%$ of diet, while huntergatherers consume only 3-50\% [34]. In the past 8,000 years, Europeans also began consuming dairy products in large quantities [35]. In comparison, South Central Asians had a much higher incidence of GDM in the NYC cohort (14.3\%) with Bangladeshis the highest at $21.2 \%$ [19]. Traditionally, Bangladeshis have had high consumption of fish, a low glycemic food; rice, of moderate glycemic index due to little processing; and no dairy [36, 37]. Finally, among African-Americans, incidence of GDM was intermediate at 4.3\% [19]. This is consistent with their admixed ancestry and the mixed consumption of dairy across populations in West Africa, the origin of most U.S. African-Americans.

Given the inverse correlation between traditional consumption of dietary components increasing GDM risk and current incidence of GDM, high glycemic foods and dairy may have acted as selective agents on metabolism during pregnancy. Since GDM is very likely to have a genetic basis - $67 \%$ of the risk of type 2 diabetes for adults younger than 60 is heritable [38], and women with GDM have 7-12x elevated risk for type 2 diabetes $[39,40]$ - natural selection can act on its underlying risk factors. Therefore, any population environmentally at risk for GDM without access to C-sections should experience selection against genetic risk factors for GDM. Conversely, any population without access to high glycemic food items should experience selection to make blood sugars more available to the fetus, perhaps through increasing insulin resistance by increasing the frequency of genetic risk factors for GDM. Supporting these predictions, evidence suggests Europeans 
may have a blunted glycemic response to food compared to other populations, which could be a result of this selection on maternal metabolism to suit diet $[41,42]$.

Like GDM, preeclampsia has an incidence that varies across populations, and it appears to have an inverse relationship with the dietary risk factor of salt-intake (Table 1) [43]. In a study of preeclampsia in NYC, preeclampsia rates were lower among immigrants from East Asia (1.4\%), especially Japan (1.2\%) and Taiwan (0.9\%), and lowest in the world among Iranians (0.6\%) [44] compared to an incidence of 3-5\% of pregnancies in other developed countries [24]. Although these populations are less obese than Americans, Japanese and Iranians have historically high salt-intakes due to consumption of coastal foods (Japan) and high soil salinity (Iran) [45-47].

High salt-consuming populations, such as Japanese and Iranians, may have experienced strong selection to protect them from the deadly threat of preeclampsia. Since the heritability of preeclampsia is 0.55 according to a study done in a Swedish cohort [48], this provides variation for selection to act on. Populations consuming large amounts of salt should experience strong selection against genetic risk factors for preeclampsia in the absence of modern medical support for premature deliveries. Supporting this, insensitivity to salt in the diet is common in Japanese: women consuming the most salt (20.6g/day) have no more hypertension than those consuming the least 8g/day [49]. For comparison, the WHO recommends less than $5 \mathrm{~g} /$ day of salt consumption for adults [50].

Adaptation for consuming a high glycemic, high dairy diet may have been the result of selection in Europeans through the pressure of GDM, whereas adaptation for consuming a high salt diet may have evolved in Japanese and Iranians through the selective pressure of preeclampsia. On the other hand, alternative hypotheses may also explain the trends 
described (see Box 2). In the past several thousand years, populations migrated to new environments and invented new methods of food extraction and processing, such as agriculture, pastoralism, and fishing. The hypotheses presented here focus on how selective pressures during pregnancy may cause strong selection in response to changing diets in recent human evolution.

\section{Nutrients and Selection during Pregnancy}

Access to nutrients has been critical in human evolution, contingent upon dietary resources and the physiological processes that determine the bioavailability of ingested nutrients. Two selective pressures in humans that changed the amount and bioavailability of nutrients in the diet were exposure to solar UV radiation and adult milk-drinking. The ways in which these impacted fecundity and pregnancy may explain why UV radiation and milk-drinking exerted such strong fitness effects.

Skin pigmentation closely correlates with UV radiation worldwide [51], perhaps partly because UV radiation exerted strong selection across populations during pregnancy in addition to other stages of life. Lighter or darker pigmentation impacts absorption of UV radiation on folate and vitamin D3, critical micronutrients during pregnancy $[51,52]$. Folate—obtained from eating plants—is stored in cutaneous blood vessels and can be destroyed by UV radiation [53]. Folate deficiency causes failure of neural tubes to close during fetal development, resulting in anencephalus and spina bifida, defects lethal to the fetus [54]. Neural tube defects rarely occur in darkly pigmented people as their melanin protects their folate stores in equatorial areas [51]. Therefore, increased melanin production among equatorial populations of Africa, as well as Asia, Australia, and the 
Pacific where populations migrated, was potentially selected to protect folate stores in the skin during pregnancy.

On the other hand, melanin in the skin also blocks synthesis of vitamin D3 at higher latitudes [55]. Vitamin D3 enables absorption of calcium for skeletal formation in the fetus and maintenance in the mother [56]. Deficiencies cause malformation of the maternal pelvis, maternal osteoporosis, and rickets in fetuses and growing children $[57,58]$. In addition, vitamin D3 may assist development of the fetal innate immune system and critical organs $[59,60]$. Therefore, balancing the synthesis of vitamin D3 with protection of folatestores for pregnancy probably played a role in the strong selection for graded melanation with UV-radiation clines worldwide [51, 52].

Signatures of strong selection have been found in diverse populations surrounding genes with variants associated with skin pigmentation—notably SLC24A5, MATP, and TYR in Europeans, DCT, EGFR, and DRD2 in East Asians, and TYRP1, KITLG, ASIP and OCA2 in both populations [61-64]. In addition, ancestral alleles of these genes that tend to be associated with darker pigmentation and occur at a high frequency in Africans also tend to be highly frequent in darkly pigmented Melanesian populations. This may indicate convergent selection on the same genetic variants in diverse populations [61], although many populations remain to be tested.

Alternatively, UV radiation may have selected for appropriate skin pigmentation at other life stages such as childhood. Some detrimental effects of UV radiation on skin, such as skin cancer, occur post-reproductively, mitigating their importance to fitness [52, 65]. However, sun-burn alone causes significant morbidity for lightly pigmented people living in high UV regions because it damages the skin, increasing infection and water loss and 
decreasing thermoregulatory control. Furthermore, while vitamin D3 is critical for pregnancy, it is also important for bone density, immune function, and other effects in childhood and throughout life. To address this, one piece of evidence indicating that pregnancy, specifically, may have been important to selection on skin pigmentation is that women exhibit slightly lower levels of skin pigmentation on low exposure patches of skin than men, across world populations, indicating that the need for vitamin D3 may have been more critical to women than men [51]. Research clarifying the importance of vitamin D3 status to human health at different life stages could shed more light on this hypothesis.

Likewise, the ability to drink milk among pastoralists who keep dairy animals may also have been driven by selection on reproductive fitness. These pastoralists experienced strong selection in the past 10,000 years to continue digesting the lactose found in milk into adulthood, rather than losing this ability shortly after birth, as in most mammals [66]. Strong selection has been detected surrounding a number of different polymorphisms in diverse pastoralist populations from Europe, Africa, the Middle East, and Central Asia, each associated with regulation of $L C T$ expression, encoding the enzyme lactase, which is responsible for cleaving lactose, the disaccharide in milk [35, 67-70]. Researchers have been surprised by the strength of this selection and have struggled to develop plausible explanations for it. Milk from animals provides an extra source of sugar, protein, fat, calcium, and hydration, beneficial not only for survival but also for reproduction. Several possible hypotheses could link milk to reproductive fitness. First, milk from animals provided a sterile source of hydration, especially for those living in hot, arid climates like Africa and the Middle East [66]. Considering the sensitivity of pregnant women to contaminated food and drink [71], pregnant women able to drink sterile fresh 
milk may have experienced special fitness benefits. Second, the extra calcium in milk could be beneficial due to its role in skeletal development and maintenance and to female reproductive maturation, as large pelvises are required for vaginal delivery [72]. Third, because fat is more calorically dense than proteins and carbohydrates, fat from milk could help the mother nourish her infant during pregnancy and lactation. Fat stores and energy balance have also been linked to age of menarche and length of anovulatory period post pregnancy $[73,74]$.

A final hypothesis involves the fact that milk and other animal fats contain cholesterols used to synthesize reproductive hormones, critical for fecundity and early fetal development and growth [75]. The grain-based diets of Neolithic farmers were lower in cholesterol than the diets of hunter-gatherer ancestors who consumed more wild game [34]. Less cholesterol in the diet correlates with lower levels of reproductive steroids [76], reducing ovarian function and fecundity, suggesting that milk drinking could have provided a much-needed cholesterol and fertility boost for Neolithic Europeans. Therefore, the increase in fat, cholesterol, and calcium from drinking milk may have accelerated female skeletal maturation, increased caloric resources, and increased fecundity among women who could consume dairy, creating strong fitness benefits.

\section{Infectious Disease and Selection during Pregnancy}

Infectious diseases have exerted some of the strongest forces of selection on humans, most notably since the increase in population densities following the transition to agriculture and pastoralism 10,000 years ago. For example, genetic variants conferring resistance to malaria, such as alleles in the region of $H B B, H B A, F Y, C D 36, G 6 P D$, etc., were 
strongly selected among African populations and others where malaria is endemic [77]. Though infectious diseases are threats to survival generally, their differential impact on infants and pregnant women makes them especially powerful selective agents.

During pregnancy, the maternal immune system is suppressed so that the mother does not launch an adaptive immune response to the fetus's foreign cellular antigens [9]. Though details are still being clarified, this response may make pregnant women less able to clear infections requiring strong inflammatory responses [9]. The outcome is that pregnant women experience spontaneous abortion and have higher morbidity and mortality in response to many infections than the general population [9].

Malaria, influenza, and cholera are three infectious diseases that pose severe risks for pregnancy. In particular, African Plasmodium falciparum can infect the placenta [9]. As a result, pregnant women with malaria die 2-3 times more often than the general infected population [78]. In sub-Saharan Africa, malaria causes $20 \%$ of the cases of low infant birthweight, along with slow growth, spontaneous abortion, maternal anemia, and infant mortality $[9,78,79]$. Intriguingly, positive selection on a genetic variant of the gene FLT1, which reduces spontaneous abortions in cases of placental malaria, has been found for a malaria-endemic population in Tanzania [80]. This indicates that in the case of malaria resistance, selection mediated by pregnant women and their fetuses alone is sufficient for adaptive change in allele frequency in a population. Based upon this evidence, although genetic variants conferring general resistance to malaria experienced positive selection that could have been mediated by a broader subset of the population, pregnant women likely comprised an important portion of this selection. 
During the 1918 influenza pandemic, $~ 50 \%$ of all infected pregnant women contracted pneumonia, and $\sim 50 \%$ of this subset died $(\sim 27 \%$ total mortality for infected pregnant women), far more than the $\sim 1 \%$ mortality for all individuals of reproductive age with influenza [81, 82]. Along with fetal abortion, this caused a 5-15\% drop in birth rate the following spring [83]. This pattern is typical of other influenza pandemics [84]. Mortality by influenza is heritable [85], so resistance to influenza may have been strongly selected for in recent human evolution, although this has been understudied.

Cholera causes diarrhea, vomiting, dehydration, and cramping, which can induce spontaneous abortion, preterm small birthweight babies, and maternal death [86]. Similar to influenza, smallpox, and dysentery, cholera decreases birthrates significantly during epidemic years $[10,87]$, indicating it has strong potential as a selective agent in humans. Many other infectious diseases are particularly dangerous for pregnant women. Among female Lassa Fever patients of childbearing years admitted to a hospital in Sierra Leone, death was significantly higher for pregnant women (25\%) than non-pregnant women (13\%) [88]. Tellingly, symptoms improved with delivery [88]. The Ebola virus killed more pregnant patients (95.5\%) than the population average $(77 \%)$ during an outbreak in the DRC [89]. Some infectious agents, for example the parasite Toxoplasma gondii, cause disease only in pregnant women, who are likely to experience abortion [9]. Evidence from mice suggests that another parasite, Leishmania, also exploits immunological changes in pregnant women [90]. Finally, Varicella zoster, the chicken pox virus, causes pregnant women to develop more skin lesions and pneumonia at higher rates than the average adult with chicken pox [91]. 
Pregnant women are clearly especially vulnerable to infectious disease. Although many of these diseases also cause significant morbidity in non-pregnant adults, the dramatic impact on pregnant women makes it likely that selective effects would have been strongly mediated by this population, though the adaptive benefit of genetic resistance to infectious disease is felt across all life stages for both males and females. As researchers discover functional genetic variants in areas under selection in the human genome, we predict that many are likely to confer resistance to infectious diseases that severely impact pregnant women who lack resistance in addition to those causing high infant mortality.

\section{Concluding remarks}

The field of human evolutionary genomics is in a period of transition. Currently, only a few examples of selection in response to environmental pressures felt by particular populations have been elucidated —-malaria resistance, lactase persistence, etc. These examples were already under study prior to the development of evolutionary genomics, and the signatures of selection surrounding the genetic variants under selection merely served to substantiate strong adaptive hypotheses already presented. However, nextgeneration sequencing data, conducted in diverse populations, now provides the raw material to detect many more strong candidates for selection. Thus, the field of evolutionary genomics now has the potential to provide many new testable hypotheses of selection, which were not developed a priori. For example, a catalog of candidate variants for selection was recently published and one of these variants was experimentally characterized [102]. 
At this turning point in the field, we seek to underscore that many aspects of human evolution are best understood by investigating the life-history bottleneck of pregnancy and birth from the perspective of both the mother and the infant. During pregnancy, nutritional, energetic, physical, and immunological requirements are constrained in the mother to support the fetus, concentrating selective forces upon the mother at a sensitive life stage. The pressures that have been most important in recent human evolution-infectious diseases from high population densities, adult dairy consumption from pastoralism, grain consumption from agriculture, changes in UV radiation and oxygen levels from moving to extreme latitudes and altitudes—have left genetic signatures of their selective impact. Although these selective factors may be felt across the lifespan, nowhere are they more serious than during infancy and pregnancy. We should thus remain cognizant of these phases of life as next-generation sequencing now provides evolutionary genomicists with the data to generate many new testable hypotheses of why loci are under selection in humans.

\section{Box 1 Oxygen and Selection during Pregnancy}

Another environmental pressure detrimental to pregnant women is high-altitude hypoxia. When brought to high-altitudes, people from sea-level populations increase hemoglobin levels to carry more oxygen to the tissues. With long-term exposure and old age, increased hemoglobin causes altitude sickness and even death. However, pregnant women experience a special danger: preeclampsia caused by oxygen-restriction for the fetus. As described in the main text, preeclampsia often results in premature labor, small birth-weight babies, and hemorrhaging, seizures, and death for the mother [24].

Tibetans, Andeans, and the Ethiopian Amhara have each adapted to hypoxic high-altitude conditions possibly due to its impact on pregnancy. In these populations, strong signatures of selection surround genetic loci related to hypoxia and hemoglobin concentration, including EGLN1, 
EPAS1, PPARA, THRB, and ARNT2 [92-95]. However, Andeans are still at risk for altitude sickness in old age because they exhibit the same elevated hemoglobin levels of low-landers at high-altitudes, indicating that selection for post-reproductive survival was not the primary force in this population [96]. Yet, some studies find that Andeans and Tibetans giving birth at high-altitudes have fewer instances of low-fetal birth weights and preeclampsia than low-landers at high-altitudes, possibly due to increased uterine capillary density [97-99]. Also, some genes under selection among the Amhara are involved in fetal hemoglobin levels (BCL11A) and angiogenesis (AIMP1 and VAV3), an important feature of pregnancy [92]. These pieces of evidence indicate that pressures during pregnancy may have been significant in adapting to high altitude hypoxia for Tibetans, Andeans, and the Amhara.

\section{Box 2 Alternative Hypotheses and Avenues of Research}

Although the evidence described in the main text support the importance of pregnancy to recent selection in humans, alternative hypotheses could also explain some phenomena that we argue suggest selection in pregnancy. Take, for example, the differences in GDM prevalence across populations, and the inverse correlation with historical glycemic intake. When mothers born in energypoor environments emigrate to energy-rich environments, fetal programming may contribute to the pattern as these women have heightened risk of GDM and type 2 diabetes [100]. Maternal epigenetic modifications could be the mechanism underlying this programming to suit the early life environment. Another contributor could be the differences in patterns of adipose storage across populations-Asian women tend to have more central adiposity than women in other populations, and this is thought to increase insulin resistance [101]. However, this proximate cause of increased GDM among Asians is not at odds with a history of natural selection acting on the trait.

Distinguishing among these competing explanations for the patterns we see could be a fruitful line of research. For example, first, one could conduct association studies in diverse ethnic populations to identify genetic loci linked to GDM risk. Second, these loci associated with GDM could be analyzed for signatures of recent selection in order to test whether selection has influenced GDM incidence across populations. Finally, one could test whether incidence of GDM among immigrants approaches that of the rest of the population across generations. GDM is reduced for South Asians born in the US compared to first generation immigrants, but it is still elevated above the level of European-Americans [19], indicating fetal programming may explain a large fraction of differences in GDM risk, but is probably not the only factor. 
Similar approaches could be used to test hypotheses of selection for resistance to preeclampsia, infectious disease, hypoxia and other reproductive factors. In a broad sense, this will require a better understanding of the axes of human variation-genetic and phenotypic. Next-generation sequencing data from diverse populations of humans will contribute to this understanding. However, the phenotypic data is just as critical. We need a clearer understanding of the susceptibility of pregnant women to infectious diseases and metabolic diseases across populations, and how this is mediated by nutritional status, UV radiation, hypoxia, and other external factors. Testing these hypotheses will be important both for evolutionary genetics and for improving care for human health across diverse ethnicities.

Table 1-Relationship between Metabolic Diseases of Pregnancy and Traditional Diets GDM Incidence, Glycemic Index, and Dairy Consumption

\begin{tabular}{|c|c|c|c|c|c|c|}
\hline Population & $\begin{array}{l}\text { GDM } \\
\text { Incidence }\end{array}$ & Diet & Dairy & Agriculture & $\begin{array}{l}\text { Glycemic } \\
\text { Index }\end{array}$ & Reference \\
\hline $\begin{array}{l}\text { European- } \\
\text { Americans }\end{array}$ & $3.6 \%$ a & $\begin{array}{l}70 \% \\
\text { Carbohydrate; } \\
\text { Grain-based }\end{array}$ & Yes & Yes & High & $15,30,31$ \\
\hline $\begin{array}{l}\text { Hunter- } \\
\text { Gatherers }\end{array}$ & $?$ & $\begin{array}{l}3-50 \% \\
\text { Carbohydrate; } \\
\text { Game, Tubers, } \\
\text { Vegetables, } \\
\text { Fruits, Nuts, etc }\end{array}$ & No & No & Moderate & 30 \\
\hline Bangladeshis & $\begin{array}{l}7-9 \%{ }^{\mathrm{b}} \\
21.2 \%{ }^{\mathrm{a}}\end{array}$ & Rice, Fish & No & Yes & Moderate & $15,32,33$ \\
\hline $\begin{array}{l}\text { African- } \\
\text { Americans }\end{array}$ & $4.3 \%{ }^{\mathrm{a}}$ & $\begin{array}{l}\text { Agriculture, } \\
\text { Pastoralism, or } \\
\text { Hunter- } \\
\text { Gatherer }\end{array}$ & Mixed & Mixed & Moderate & 15 \\
\hline \multicolumn{7}{|c|}{ Preeclampsia Incidence and Traditional Salt Consumption } \\
\hline Population & $\begin{array}{l}\text { Preeclampsia } \\
\text { Incidence }\end{array}$ & $\begin{array}{l}\text { Salt } \\
\text { Consumption }\end{array}$ & Obesity & & & Reference \\
\hline $\begin{array}{l}\text { European- } \\
\text { Americans }\end{array}$ & $2 \%{ }^{\mathrm{a}}$ & $?$ & High & & & 40,41 \\
\hline $\begin{array}{l}\text { Sub- } \\
\text { Saharans }\end{array}$ & $3.3-3.9 \% \%^{\mathrm{a}}$ & $\begin{array}{l}\text { Low, especially } \\
\text { in rainforests }\end{array}$ & Low & & & 40,41 \\
\hline $\begin{array}{l}\text { African- } \\
\text { Americans }\end{array}$ & $4.6 \% \%^{a}$ & $\begin{array}{l}\text { Low, mixed } \\
\text { ancestry }\end{array}$ & High & & & 40,41 \\
\hline Iranians & $0.6 \%^{a}$ & $\begin{array}{l}\text { High, due to soil } \\
\text { salinity }\end{array}$ & Medium & & & $40,41,42$ \\
\hline
\end{tabular}




\begin{tabular}{lll}
\hline Japanese $1.2 \% \mathrm{a}^{\mathrm{a}}$ & $\begin{array}{l}\text { High, due to } \\
\text { seafood }\end{array}$ & Medium \\
\hline $\begin{array}{l}\text { aIncidence for populations living in New York City } \\
\text { bIncidence for populations living in Bangladesh }\end{array}$ & $40,41,43$ \\
\hline
\end{tabular}

1 Graunt, J. (1662) Natural and political observations mentioned in a following index, and made upon the bills of mortality.

2 Butte, N.F. (2000) Carbohydrate and lipid metabolism in pregnancy: normal compared with gestational diabetes mellitus. The American journal of clinical nutrition 71, 1256S$1261 \mathrm{~S}$

3 Pritchard, J. (1965) Changes in the blood volume during pregnancy and delivery. Anesthesiology

4 Kaufmann, P., et al. (2004) Aspects of human fetoplacental vasculogenesis and angiogenesis. II. Changes during normal pregnancy. Placenta 25, 114-126

5 Sladek, S.M., et al. (1997) Nitric oxide and pregnancy. The American journal of physiology 272, R441-463

6 Hermida, R.C., et al. (2000) Blood Pressure Patterns in Normal Pregnancy, Gestational Hypertension, and Preeclampsia. Hypertension 36, 149-158

7 Jolly, M.C., et al. (2003) Risk factors for macrosomia and its clinical consequences: a study of 350,311 pregnancies. European Journal of Obstetrics \& Gynecology and Reproductive Biology 111, 9-14

8 James, A.H., et al. (2005) Incidence and risk factors for stroke in pregnancy and the puerperium. Obstetrics and gynecology 106, 509-516

9 Robinson, D.P. and Klein, S.L. (2012) Pregnancy and pregnancy-associated hormones alter immune responses and disease pathogenesis. Hormones and behavior

10 Woods, R. (2009) Death before Birth. Oxford University Press

11 Marlowe, F.W. (2005) Hunter-gatherers and human evolution. Evolutionary

Anthropology: Issues, News, and Reviews 14, 54-67

12 Rajaratnam, J.K., et al. (2010) Neonatal, postneonatal, childhood, and under-5 mortality

for 187 countries, 1970-2010: a systematic analysis of progress towards Millennium Development Goal 4. Lancet 375, 1988-2008

13 Ronsmans, C. and Graham, W.J. (2006) Maternal mortality: who, when, where, and why. Lancet 368, 1189-1200

14 Courtiol, A., et al. (2012) Natural and sexual selection in a monogamous historical human population. Proceedings of the National Academy of Sciences of the United States of America 109, 8044-8049

$15 \mathrm{Liu}$, J., et al. (2012) Maternal risk of breeding failure remained low throughout the demographic transitions in fertility and age at first reproduction in Finland. PLoS ONE 7, e34898 
16 Laland, K.N., et al. (2010) How culture shaped the human genome: bringing genetics and the human sciences together. Nature reviews. Genetics 11, 137-148

17 Moreau, C., et al. (2011) Deep human genealogies reveal a selective advantage to be on an expanding wave front. Science (New York, N.Y.) 334, 1148-1150

18 Barbour, L.a., et al. (2007) Cellular mechanisms for insulin resistance in normal pregnancy and gestational diabetes. Diabetes care 30 Suppl 2, S112-119

19 Savitz, D.a., et al. (2008) Ethnicity and gestational diabetes in New York City, 1995-2003. BJOG : an international journal of obstetrics and gynaecology 115, 969-978

20 Langer, 0., et al. (2005) Gestational diabetes: the consequences of not treating. American journal of obstetrics and gynecology 192, 989-997

21 Sermer, M., et al. (1998) The Toronto Tri-Hospital Gestational Diabetes Project. A

preliminary review. Diabetes care 21 Suppl 2, B33-42

22 Rosenberg, K. and Trevathan, W. (2002) Birth, obstetrics and human evolution. BJOG :

an international journal of obstetrics and gynaecology 109, 1199-1206

23 Dunsworth, H.M., et al. (2012) Metabolic hypothesis for human altriciality. Proceedings

of the National Academy of Sciences of the United States of America 109, 15212-15216

24 WHO (2005) World Health Report: Make every mother and child count.

25 Moodley, J. (2008) Maternal deaths due to hypertensive disorders in pregnancy. Best

practice \& research. Clinical obstetrics \& gynaecology 22, 559-567

26 Duley, L. (1992) Maternal mortality associated with hypertensive disorders of

pregnancy in Africa, Asia, Latin America and the Caribbean. British journal of obstetrics and gynaecology $99,547-553$

27 Hunsberger, M., et al. (2010) Racial/ethnic disparities in gestational diabetes mellitus: findings from a population-based survey. Women's health issues : official publication of the Jacobs Institute of Women's Health 20, 323-328

28 Caughey, A.B., et al. (2010) Maternal and paternal race/ethnicity are both associated with gestational diabetes. American journal of obstetrics and gynecology 202, 616.e611615

29 Holt, S., et al. (1997) An insulin index of foods: the insulin demand generated by $1000-\mathrm{kJ}$ portions of common foods. The American journal of clinical, 1264-1276

30 Hoyt, G., et al. (2007) Dissociation of the glycaemic and insulinaemic responses to whole and skimmed milk. British Journal of Nutrition 93, 175

31 Zhang, C., et al. (2006) Dietary fiber intake, dietary glycemic load, and the risk for gestational diabetes mellitus. Diabetes care 29, 2223-2230

32 Zhang, C. and Ning, Y. (2011) Effect of dietary and lifestyle factors on the risk of gestational diabetes: review of epidemiologic evidence. The American journal of clinical nutrition 94, 1975S-1979S

33 Hoppe, C., et al. (2005) High intakes of milk, but not meat, increase s-insulin and insulin resistance in 8-year-old boys. European journal of clinical nutrition 59, 393-398

34 Ströhle, A. and Hahn, A. (2011) Diets of modern hunter-gatherers vary substantially in their carbohydrate content depending on ecoenvironments: results from an ethnographic analysis. Nutrition research (New York, N.Y.) 31, 429-435

35 Myles, S., et al. (2005) Genetic evidence in support of a shared Eurasian-North African dairying origin. Human genetics 117, 34-42

36 Itan, Y., et al. (2010) A worldwide correlation of lactase persistence phenotype and genotypes. BMC evolutionary biology 10, 36-47 
37 Atkinson, F.S., et al. (2008) International tables of glycemic index and glycemic load values: 2008. Diabetes care 31, 2281-2283

38 Almgren, P., et al. (2011) Heritability and familiality of type 2 diabetes and related quantitative traits in the Botnia Study. Diabetologia 54, 2811-2819

39 Metzger, B.E., et al. (2007) Summary and recommendations of the Fifth International Workshop-Conference on Gestational Diabetes Mellitus. Diabetes care 30 Suppl 2, S251260

40 Bellamy, L., et al. (2009) Type 2 diabetes mellitus after gestational diabetes: a systematic review and meta-analysis. Lancet 373, 1773-1779

41 Dickinson, S., et al. (2002) Postprandial Hyperglycemia and Insulin Sensitivity Differ among Lean Young Adults of Different Ethnicities. The Journal of Nutrition, 2574-2579 42 Henry, C.J.K., et al. (2008) Glycaemic index of common foods tested in the UK and India. The British journal of nutrition 99, 840-845

43 Reyes, L., et al. (2012) Nutritional status among women with pre-eclampsia and healthy pregnant and non-pregnant women in a Latin American country. The journal of obstetrics and gynaecology research 38, 498-504

44 Gong, J., et al. (2012) Maternal ethnicity and pre-eclampsia in New York City, 19952003. Paediatric and perinatal epidemiology $26,45-52$

45 INTERSALT (1988) Intersalt: an international study of electrolyte excretion and blood pressure. Results for 24 hour urinary sodium and potassium excretion. Intersalt Cooperative Research Group. BMJ (Clinical research ed.) 297, 319-328

46 FAO, et al. (2012) Harmonized World Soil Database (version 1.2). (FAO and IIASA, eds) 47 Brown, I.J., et al. (2009) Salt intakes around the world: implications for public health. International journal of epidemiology 38, 791-813

48 Cnattingius, S., et al. (2004) Maternal and fetal genetic factors account for most of familial aggregation of preeclampsia: a population-based Swedish cohort study. American journal of medical genetics. Part A 130A, 365-371

49 Miura, K., et al. (2010) Dietary Salt Intake and Blood Pressure in a Representative Japanese Population: Baseline Analyses of NIPPON DATA80. Journal of Epidemiology 20, S524-S530

50 WHO (2010) Global status report on non-communicable diseases 2010.

51 Jablonski, N.G. and Chaplin, G. (2000) The evolution of human skin coloration. Journal of Human Evolution 39, 57-106

52 Jablonski, N.G. and Chaplin, G. (2010) Colloquium paper: human skin pigmentation as an adaptation to UV radiation. Proceedings of the National Academy of Sciences of the United States of America 107 Suppl 8962-8968

53 Steindal, A.H., et al. (2008) 5-Methyltetrahydrofolate is photosensitive in the presence of riboflavin. Photochemical \& Photobiological Sciences 7, 814

54 Fleming, A. and Copp, A.J. (1998) Embryonic folate metabolism and mouse neural tube defects. Science (New York, N.Y.) 280, 2107-2109

55 Holick, M.F. (1987) Photosynthesis of vitamin D in the skin: effect of environmental and life-style variables. Federation proceedings 46, 1876-1882

56 Brunvand, L., et al. (1996) Vitamin D deficiency and fetal growth. Early human

development 45, 27-33 
57 Fogelman, Y., et al. (1995) High prevalence of vitamin D deficiency among Ethiopian women immigrants to Israel: exacerbation during pregnancy and lactation. Israel journal of medical sciences $31,221-224$

58 Henderson, J.B., et al. (1987) The importance of limited exposure to ultraviolet radiation and dietary factors in the aetiology of Asian rickets: a risk-factor model. The Quarterly journal of medicine $63,413-425$

59 Norman, A.W. (2008) From vitamin D to hormone D: fundamentals of the vitamin D endocrine system essential for good health. The American journal of clinical nutrition 88, 491S-499S

60 Holick, M.F. (2004) Vitamin D: importance in the prevention of cancers, type 1 diabetes, heart disease, and osteoporosis. The American journal of clinical nutrition 79, 362-371 61 Lao, O., et al. (2007) Signatures of positive selection in genes associated with human skin pigmentation as revealed from analyses of single nucleotide polymorphisms. Annals of human genetics 71, 354-369

62 Norton, H.L., et al. (2007) Genetic evidence for the convergent evolution of light skin in Europeans and East Asians. Molecular biology and evolution 24, 710-722

63 Alonso, S., et al. (2008) Complex signatures of selection for the melanogenic loci TYR, TYRP1 and DCT in humans. BMC evolutionary biology 8, 74

64 Quillen, E.E., et al. (2012) OPRM1 and EGFR contribute to skin pigmentation differences between Indigenous Americans and Europeans. Human genetics 131, 1073-1080 65 Blum, H. (1961) Does the Melanin Pigment of Human Skin Have Adaptive Value?: An Essay in Human Ecology and the Evolution of Race. Quarterly Review of Biology 36, 50-63 66 Ingram, C.J.E., et al. (2009) Lactose digestion and the evolutionary genetics of lactase persistence. Human genetics 124, 579-591

67 Tishkoff, S.A., et al. (2007) Convergent adaptation of human lactase persistence in Africa and Europe. Nature genetics 39, 31-40

68 Enattah, N.S., et al. (2008) Independent Introduction of Two Lactase-Persistence Alleles into Human Populations Reflects Different History of Adaptation to Milk Culture. Journal of Human Genetics 82, 57-72

69 Peng, M.-S., et al. (2012) Lactase persistence may have an independent origin in Tibetan populations from Tibet, China. Journal of human genetics 57, 394-397

70 Heyer, E., et al. (2011) Lactase persistence in central Asia: phenotype, genotype, and evolution. Human biology 83, 379-392

71 Pouillot, R., et al. (2012) Relative risk of listeriosis in Foodborne Diseases Active Surveillance Network (FoodNet) sites according to age, pregnancy, and ethnicity. Clinical infectious diseases : an official publication of the Infectious Diseases Society of America 54 Suppl 5, S405-410

72 Ellison, P.T. (1990) Human Ovarian Function and Reproductive Ecology: New Hypotheses. American Anthropologist 92, 933-952

73 Frisch, R.E. (1984) Body fat, puberty and fertility. Biological reviews of the Cambridge Philosophical Society 59, 161-188

74 Panter-Brick, C., et al. (1993) Seasonality of reproductive function and weight loss in rural Nepali women. Human reproduction (Oxford, England) 8, 684-690

75 Herrera, E. (2002) Lipid metabolism in pregnancy and its consequences in the fetus and newborn. Endocrine 19, 43-55 
76 Goldin, B.R., et al. (1982) Estrogen excretion patterns and plasma levels in vegetarian and omnivorous women. The New England journal of medicine 307, 1542-1547

77 Campino, S., et al. (2006) Mendelian and complex genetics of susceptibility and resistance to parasitic infections. Seminars in immunology 18, 411-422

78 Shulman, C. (2003) Importance and prevention of malaria in pregnancy. Transactions of the Royal Society of Tropical, 30-35

79 Steketee, R.W., et al. (2001) The burden of malaria in pregnancy in malaria-endemic areas. The American journal of tropical medicine and hygiene 64, 28-35

80 Muehlenbachs, A., et al. (2008) Natural selection of FLT1 alleles and their association with malaria resistance in utero. Proceedings of the National Academy of Sciences of the United States of America 105, 14488-14491

81 Harris, J. (1919) Influenza occurring in pregnant women. Journal of the American Medical Association

82 Taubenberger, J.K. and Morens, D.M. (2006) 1918 Influenza: the mother of all pandemics. Emerging infectious diseases 12, 15-22

83 Bloom-Feshbach, K., et al. (2011) Natality decline and miscarriages associated with the 1918 influenza pandemic: the Scandinavian and United States experiences. The Journal of infectious diseases 204,1157-1164

84 Pazos, M., et al. (2012) The influence of pregnancy on systemic immunity. Immunologic research

85 Horby, P., et al. (2012) The role of host genetics in susceptibility to influenza: a systematic review. PloS one 7, e33180

86 Carrera, J. (2007) Recommendations and Guidelines for Perinatal Medicine.

87 Hotelling, H. and Hotelling, F. (1931) Causes of birth rate fluctuations. Journal of the American Statistical Association 26, 135-149

88 Price, M.E., et al. (1988) A prospective study of maternal and fetal outcome in acute Lassa fever infection during pregnancy. BMJ (Clinical research ed.) 297, 584-587 89 Mupapa, K., et al. (1999) Ebola hemorrhagic fever and pregnancy. The Journal of infectious diseases 179 Suppl 1, S11-12

90 Roberts, C. and Walker, W. (2001) Sex-Associated Hormones and Immunity to Protozoan Parasites. Clinical Microbiology 14

91 Harger, J.H., et al. (2002) Risk factors and outcome of varicella-zoster virus pneumonia in pregnant women. The Journal of infectious diseases 185, 422-427

92 Scheinfeldt, L.B., et al. (2012) Genetic adaptation to high altitude in the Ethiopian highlands. Genome biology 13, R1

93 Bigham, A., et al. (2010) Identifying Signatures of Natural Selection in Tibetan and Andean Populations Using Dense Genome Scan Data. PLoS Genetics 6, e1001116

94 Beall, C.M., et al. (2010) Natural selection on EPAS1 (HIF2\{alpha\}) associated with low hemoglobin concentration in Tibetan highlanders. Proceedings of the National Academy of Sciences of the United States of America 107, 11459-11464

95 Simonson, T.S., et al. (2010) Genetic Evidence for High-Altitude Adaptation in Tibet. Science (New York, N.Y.) 72

96 Mejía, O.M., et al. (2005) Genetic association analysis of chronic mountain sickness in an Andean high-altitude population. Haematologica 90, 13-19

97 Moore, L.G., et al. (2001) Oxygen transport in tibetan women during pregnancy at 3,658 m. American journal of physical anthropology 114, 42-53 
98 Wilson, M.J., et al. (2007) Greater uterine artery blood flow during pregnancy in multigenerational (Andean) than shorter-term (European) high-altitude residents. American journal of physiology. Regulatory, integrative and comparative physiology 293, R1313-1324

99 Beall, C.M. (2007) Two routes to functional adaptation: Tibetan and Andean highaltitude natives. Proceedings of the National Academy of Sciences of the United States of America 104 Suppl 8655-8660

100 Hales, C.N. and Barker, D.J. (2001) The thrifty phenotype hypothesis. British medical bulletin $60,5-20$

101 Raji, a., et al. (2001) Body fat distribution and insulin resistance in healthy Asian Indians and Caucasians. The Journal of clinical endocrinology and metabolism 86, 53665371

102 Grossman, S.R., et al. (2013) Identifying Recent Adaptations in Large-Scale Genomic Data. Cell 152, 703-713

103 Heron, M. (2012) Deaths: leading causes for 2009. National vital statistics reports :

from the Centers for Disease Control and Prevention, National Center for Health Statistics, National Vital Statistics System 61, 1-95 
Figure 1. Multiple Varied Causes of Death in Modern and Historic Populations

(a) Reported Causes of Death in London, 1632

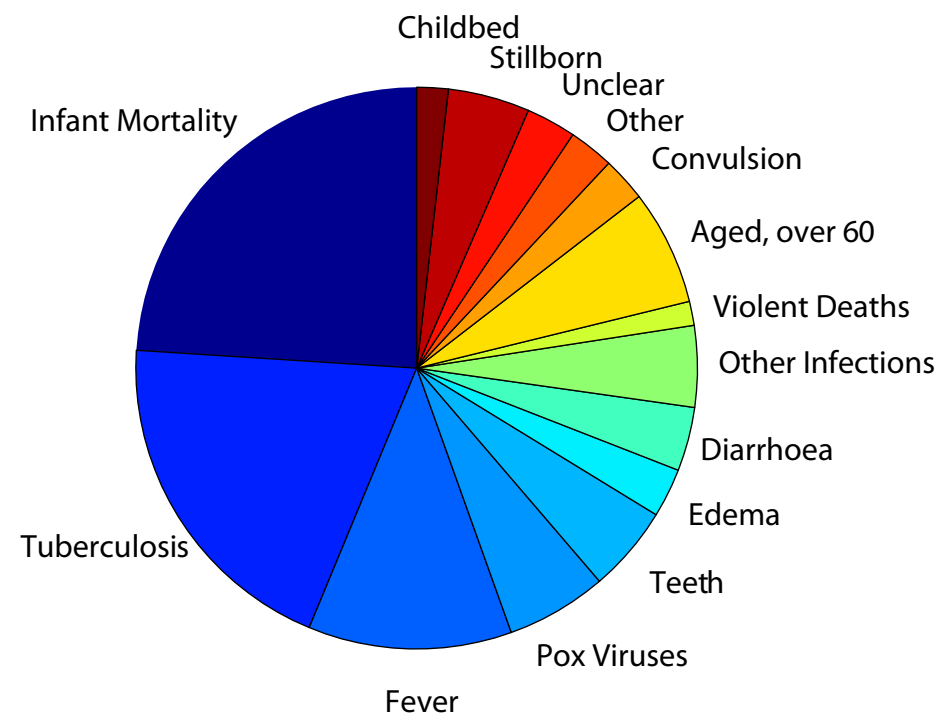

(b) Ten Leading Causes of Death in US, 2009

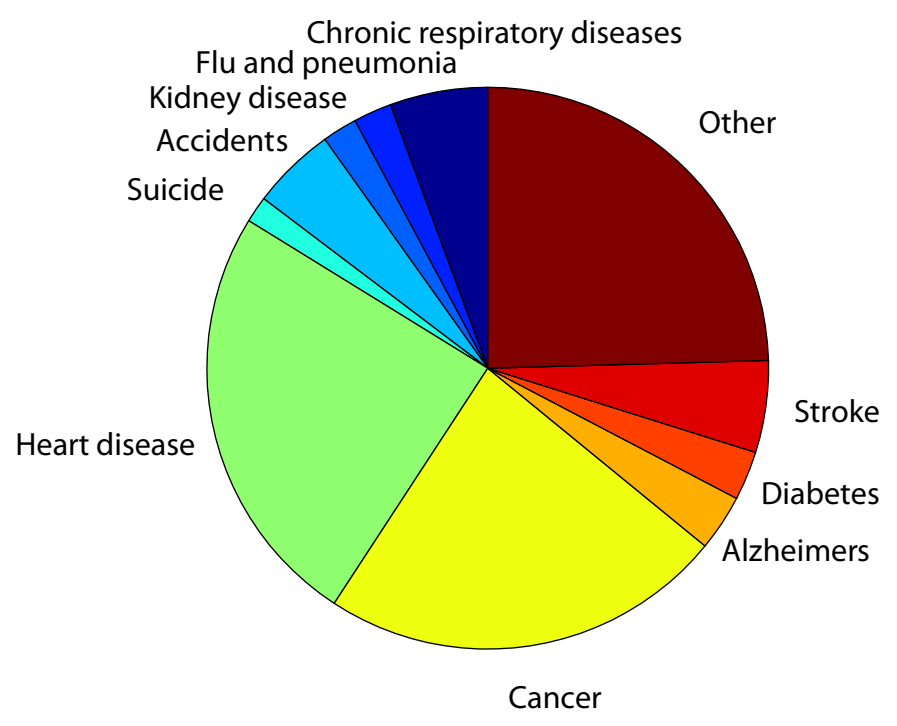

Figure 1 Multiple Varied Causes of Death in Modern and Historic Populations (a) Many different factors caused death for individuals who died in London in 1632 [1]. "Childbed" referred to mothers who died during or after labor, often due to infections. Over a quarter of deaths occurred in infants and unborn fetuses. (b) By contrast, the leading causes of death in modern, developed countries, such as the US in 2009, are very different with heart disease and cancer accounting for fully half of the deaths [103]. 
Figure 2. Rapid Change in Prevlance of Fertility Enhancing Traits

(a) Fertility in Finnish Women

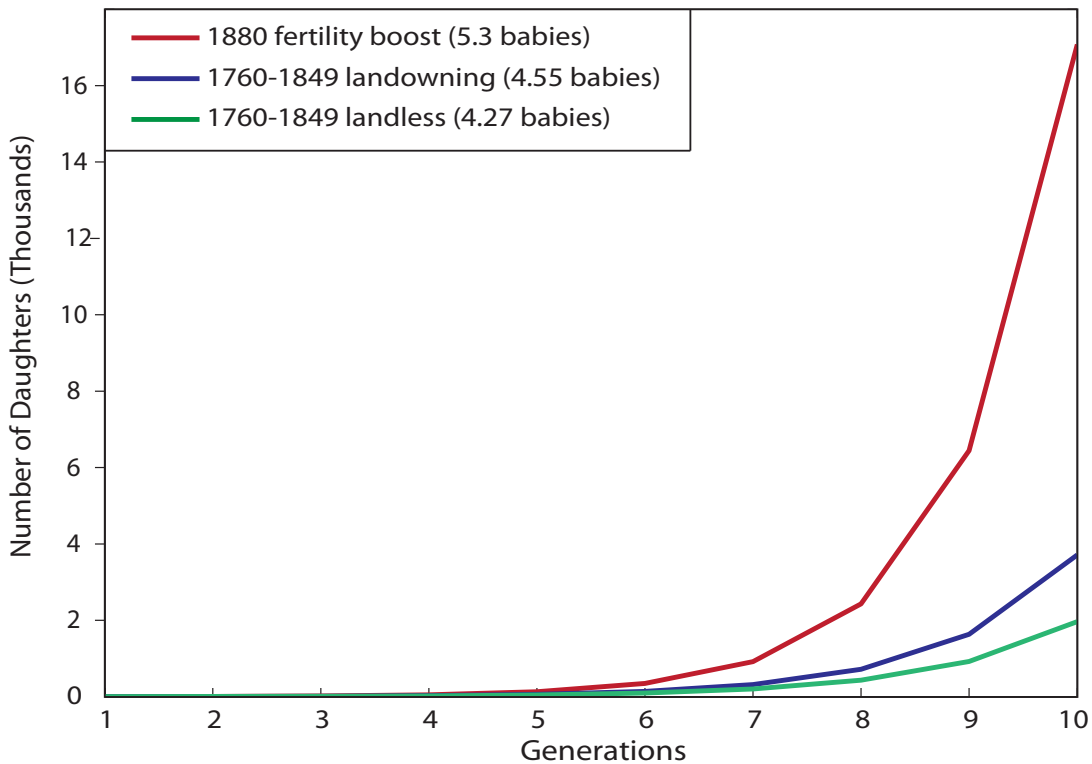

(b)

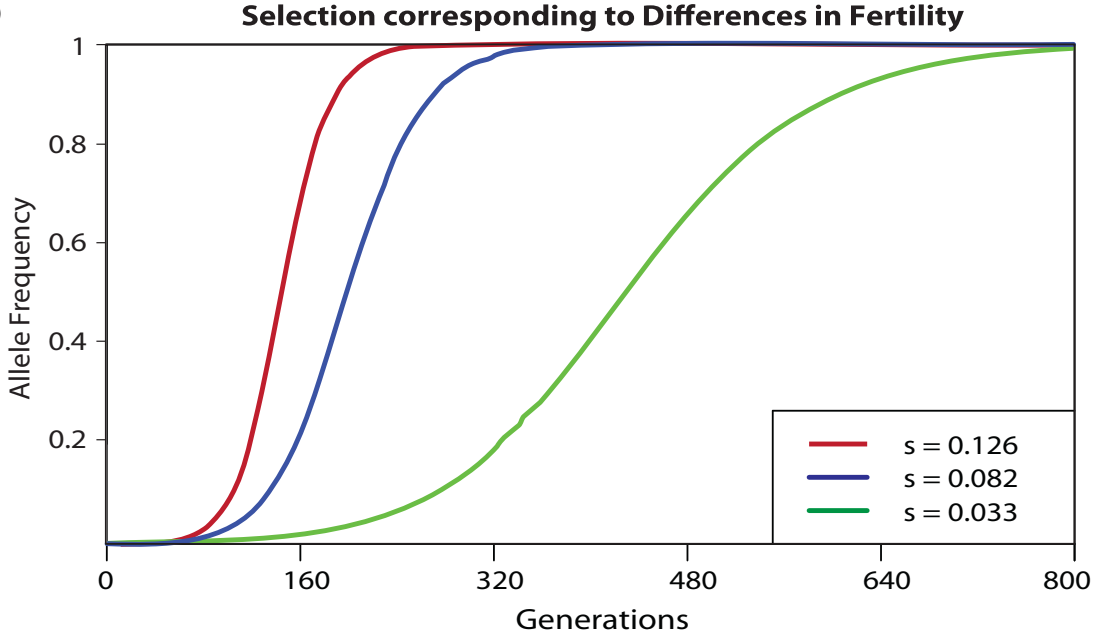

Figure 2 Rapid Change in Prevalence of Fertility Enhancing Traits (a) The increase in number of female descendants ( $y$-axis in the thousands), compounded across generations, for maternal lineages with an average of $5.3,4.55$, or 4.27 babies over a lifetime, based on pre-industrial data on differences in female fertility in Finland $[14,15]$. (b) The increase in frequency of new mutations conferring fertility advantages that correspond to the differences in fertility for the three groups of Finnish women ( $s=0.126$ for 5.3 versus 4.27 babies; $\mathrm{s}=0.82$ for 5.3 versus 4.55 babies; $\mathrm{s}=0.033$ for 4.55 versus 4.27 babies). This demonstrates how readily any mutation with a positive impact on female reproduction will sweep through a population over a very short time due to the compounding effect across generations. 